\title{
Coercion and undue influence in decisions to participate in psychiatric research - research findings Charles Lidz
}

\author{
Address: UMass Medical School, 55 Lake Ave North, Worcester, MA 01655, USA \\ from WPA Thematic Conference. Coercive Treatment in Psychiatry: A Comprehensive Review \\ Dresden, Germany. 6-8 June 2007 \\ Published: 19 December 2007 \\ BMC Psychiatry 2007, 7(Suppl I):SI 40 doi:I0.II86/I47I-244X-7-SI-SI 40
}

This abstract is available from: http://www.biomedcentral.com/I47I-244X/7/SI/SI40

(c) 2007 Lidz; licensee BioMed Central Ltd.

Research on coercion in research contexts is almost unknown. Much of the difficulty is conceptual and methodological. We do not have general agreement on what should be counted as coercive in a research context and how it should be measured. This paper will review the limited data on the subject and the methodologies and findings that have been used in clinical contexts. These methodologies, while providing a good starting place for research on coercion in research, do not solve the problem because of both differences in the contexts in which research and clinical care are undertaken and because research takes place in a different normative context. The paper will show both how these contexts limit the applicability of the existing clinical research and what might be taken from prior research that would be applicable. The paper will also present some preliminary data from a study that seeks to develop a mechanism for assessing voluntariness in the context of clinical research. 